\title{
Experimental investigation on asphaltene biodegradability using microorganism: cell surface properties' approach
}

\author{
Shohreh Iraji ${ }^{1}$ Shahab Ayatollahi ${ }^{1}$ (I)
}

Received: 5 May 2018 / Accepted: 20 August 2018 / Published online: 12 September 2018

(c) The Author(s) 2018

\begin{abstract}
Asphaltene precipitation is known to be responsible for serious challenges in oil industry such as wellbore damage, oil flow reduction, and plugging of transportation lines. The traditional methods to remove asphaltene deposition are mostly based on chemical solvent. One of the recent proposed green and cost-effect remedial methods is the application of microorganisms capable of consuming the heavy hydrocarbon chains. The cell surface hydrophobicity among others effectively manipulates the efficiency of the microorganism for asphaltene degradation. Besides, surface active agents would affect the microorganism adhesion and cell surface properties, and alters its hydrophobicity. Investigating the effect of these parameters on biodegradability of asphaltene leads to a better understanding of the microorganism effects on asphaltenic oil. In the current investigation, different asphaltenic solutions with the concentration of 2, 4, and $10 \mathrm{~g} / \mathrm{l}$ are prepared using different southern Iranian crude oil sources, namely Ahwaz-Bangestan and Kuh-e-Mond oil fields. To estimate asphaltene biodegradability, the solutions were used as a carbon source for three different microorganisms namely Enterobacter cloacae, Enterobacter cloacae, and Pseudomonas aeruginosa for a period of 10 days, while the temperature and rotational speed were kept constant under $40{ }^{\circ} \mathrm{C}$ and $150 \mathrm{rpm}$, respectively. The tests were also repeated using sodium dodecyl benzene sulfonate as surface active agent to evaluate the effect of surfactant on microorganism adhesion and cell surface hydrophobicity. The results pointed to the direct effects of the initial concentration of asphaltene in the solution as well as the presence of surfactant which alters the cells hydrophobicity and leads to more asphaltene biodegradability up to $49 \%$.
\end{abstract}

Keywords Asphaltene $\cdot$ Biodegradation $\cdot$ Hydrophobicity $\cdot$ Microorganism

\section{Introduction}

Asphaltenes are complex high-molecular-weight compounds which are soluble in aromatics and their derivatives such as toluene, however, insoluble in n-Paraffins $\left(\mathrm{n}-\mathrm{C}_{5}\right.$ and $\mathrm{n}-\mathrm{C}_{7}$; in general) (Ali and Al-Ghannam 1981; Mullins 2008). Because of thermodynamic equilibrium between the crude oil components, asphaltene is naturally suspended in crude oil; however, any disturbance such as pressure or composition changes results in accumulation and precipitation of asphaltene. Hydrocarbon production from oil reservoirs as well as fluids injection for secondary or tertiary oil recovery would affect the thermodynamic equilibrium which result in asphaltene precipitation and deposition in the reservoir

Shahab Ayatollahi

Shahab@Sharif.ir

1 School of Chemical and Petroleum Engineering, Sharif University of Technology, Tehran, Iran and production facilities (Escobedo and Mansoori 2010; Kor et al. 2017; Mansoori 2009; Rabbani et al. 2018). Different remedial methods for removing asphaltene deposits have been proposed and implemented from which application of aromatic solvent including toluene and xylene is among the most widely used (Mansoori and Elmi 2010). As a result of the high price of these materials and the global concern on the effect of aromatic solvent on environment, there is a tendency to find more environmentally friendly and less costly alternatives. A recent proposed method is to make use of the microorganisms which are able to consume the heavy hydrocarbon chains, including asphaltene, in wellbores and surface facilities.

The possibility of asphaltene molecules degradation by microorganisms has been investigated by several researchers. It is reported that the presence of hydrogen, nitrogen, and oxygen atoms in asphaltene which are crucial for bacterial activities will assist the degradation process (Etoumi et al. 2008; Kloos et al. 2006; Liao et al. 2009; Reddy et al. 2011;

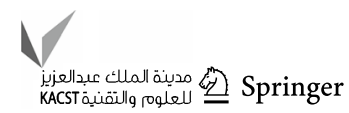


Silva et al. 2008). Pendrys using an enrichment technique isolated seven species of Gram-negative, aerobic asphaltene degrading bacteria. A mixed culture of these bacteria was capable of consuming the saturated and naphthenic aromatic parts of asphaltene compound (Pendrys 1989). Ferrari et al. (1993) investigated different species of microorganisms with higher metabolic capacity which were able to consume several instances of hydrocarbons with higher biodegradation resistance including aromatics, resins, and asphaltenes. Pineda-Flores and Mesta-Howard (2001) successfully isolate a culture of microorganisms from Maya oil which were capable of biodegrading asphaltenes as a source of carbon and energy. Tavassoli et al. (2012) studied asphaltene biodegradability using five selective microorganisms from one of the southern Iranian oil reservoirs. Jahromi et al. investigated asphaltene biodegradability under static and shaking conditions. After isolating microorganisms from oil contaminated soils and sludge and discretize them into four bacterial groups, they introduced asphaltene as the only carbon and energy source to the bacteria consortiums. In period of 2 months, while the temperature and $\mathrm{pH}$ were kept constant under $40{ }^{\circ} \mathrm{C}$ and 6.86 , the highest biodegradation reported to be $51.5 \%$ and $32 \%$ for shaking and static conditions, respectively (Jahromi et al. 2014).

Complex asphaltene molecular structure, low rate of mass transfer between asphaltene particles and biocatalysts, and low asphaltene penetration into the cell membrane are among the causes of high resistance of these compounds to biological conversion (Bressler and Gray 2003). In addition, high hydrophobicity of asphaltene molecules will result in low mass transfer rate in aqueous phase (Gray 1994). Adhesion to asphaltene surface is the key factor in growth of asphaltene consuming bacteria. It has been reported that growth of consumer bacteria is directly related to their adhesion to the oil-water contact, or in the case of asphaltene biological degradation, adhesion to asphaltene-water interface (Rosenberg and Rosenberg 1981). Chemical surfactants can positively affect biodegradation and introducing them to system will modify cell surface (Kaczorek et al. 2008, 2010). By introducing chemical surfactants to the system, surfactant polar hydrophilic head penetrates into microorganism cell surface; concurrently, surfactant nonpolar hydrophobic tail alters the cell surface to a more hydrophobic nature (Abbasnezhad et al. 2008).

The partitioning coefficient of a surfactant between oil and water is related to the free energy of transfer from one phase to the other. Salager et al. (2000) reported the influence of temperature on the partition coefficient of a surfactant between oil and water. Zhang et al. studied the influence of asphaltene concentration of two typical. With the increase of asphaltene concentration, the demulsifiers' adsorption rates increased, but the reorganization rates on the interface decreased (Zhang et al. 2016). Torrealba et al. introduced a model that predicts interfacial tensions for all microemulsion Winsor types and overall compositions. The approach predicts two- and three-phase interfacial tensions and phase behavior (i.e., tie lines and tie triangles) for changes in composition and hydrophilic-lipophilic deviation (HLD) input parameters, such as temperature, pressure, surfactant structure, and oil equivalent alkane carbon number (Torrealba and Johns 2017). They also presented a simple approach for capturing surfactant partitioning as a function of HLD and coupled with a microemulsion-phase-behavior models (Torrealba and Johns 2018).

In this work, the degradation ability of several different microorganisms and the effect of sodium dodecyl benzene sulfonate (SDBS) surfactant on their cell surface properties for the biodegradation of asphaltene deposits are investigated.

\section{Materials and methods}

\section{Asphaltene extraction}

Heavy oil samples from Ahwaz-Bangestan and Kuh-e-Mond reservoirs were utilized in this study. The densities of oil samples are 23.8 and 12.8 API degrees, respectively, and the results of SARA tests shows the weight percent of saturated, aromatics, resins, and asphaltene components which are, respectively, 42, 43, 8, and 7 for Ahwaz-Bangestan oil sample and 12.8, 21.83, 53.39, and 14.7 for Kuh-e-Mond oil sample. Asphaltene was extracted from the oil samples using ASTM D3279-90 (https://www.astm.org/Standards/D3279 .htm) recommended procedure.

Figure 1 demonstrates the proposed molecular structure of the extracted asphaltene (Amin et al. 2011).

\section{Microorganisms}

Various types of available microorganisms were screened and three were selected for their compatibility to saline environment (up to $15 \%$ ) and high thermal media. Table 1 presents the properties of the selected microorganisms.

\section{Preparation of bacterial solution}

Mineral salt solution (MSS) (Sarafzadeh et al. 2014) was selected and prepared as a growth medium for microorganisms. The growth medium contained the following composition $\left(\mathrm{kg} / \mathrm{m}^{3}\right): \mathrm{K}_{2} \mathrm{HPO}_{4} ; 7.2, \mathrm{KH}_{2} \mathrm{PO}_{4} ; 13.9, \mathrm{NaCl} ; 1, \mathrm{NaNO}_{3}$; 1 and yeast extract; 0.5 . This medium was autoclaved, and then, $1 \mathrm{vol} \%$ of each of the following solutions were added: $\left(\mathrm{NH}_{4}\right)_{2} \mathrm{SO}_{4} ; 10 \%(\mathrm{w} / \mathrm{w}), \mathrm{MgSO}_{4} ; 2.5 \%(\mathrm{w} / \mathrm{w})$ and trace element solution of Velin (Sarafzadeh et al. 2014). The trace element solution contained the following composition 

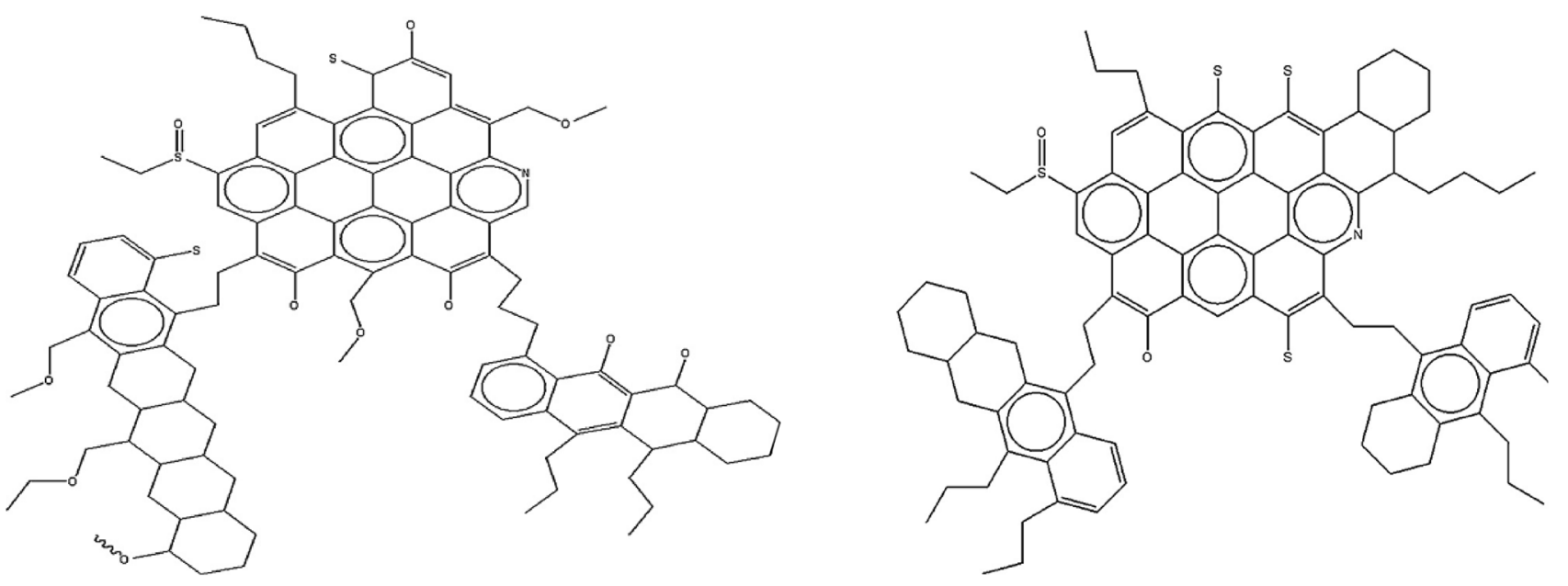

Fig. 1 Proposed molecular structure for asphaltene sample extracted from left: Bangestan oil and right: Kuh-e-Mond oil (Amin et al. 2011)

Table 1 Utilized microorganisms for asphaltene biodegradation

\begin{tabular}{lll}
\hline Bacteria genera & Accession number & Biological property \\
\hline Enterobacter cloacae (A) & - & Gram-negative \\
Enterobacter cloacae (B) & $H M 748462$ & Gram-negative \\
Pseudomonas aeruginosa & $R 7-803$ & Gram-negative \\
(C) & & \\
\hline
\end{tabular}

(g/l): ethylenediaminetetraacetic acid (EDTA); 0.5, NaCl; $1, \mathrm{MnSO}_{4} \cdot \mathrm{H}_{2} \mathrm{O} ; 3, \mathrm{CaCl}_{2} \cdot 2 \mathrm{H}_{2} \mathrm{O} ; 0.1, \mathrm{ZnSO}_{4} \cdot 7 \mathrm{H}_{2} \mathrm{O} ; 0.1$, $\mathrm{CuSO}_{4} \cdot 5 \mathrm{H}_{2} \mathrm{O} ; 0.1, \mathrm{AlK}\left(\mathrm{SO}_{4}\right)_{2} ; 0.01, \mathrm{Na}_{2} \mathrm{MoO}_{4} \cdot 2 \mathrm{H}_{2} \mathrm{O}$ $0.01, \mathrm{Na}_{2} \mathrm{SeO}_{4} ; 0.005, \mathrm{NiCl}_{2} \cdot 6 \mathrm{H}_{2} \mathrm{O} ; 0.003, \mathrm{FeSO}_{4} \cdot 7 \mathrm{H}_{2} \mathrm{O}$; 0.1 and $\mathrm{H}_{3} \mathrm{BO}_{4} ; 0.01$. Prior to adding the above solutions to the growth media, the first two were autoclaved and the last was sterilized using microbial filter for its high thermal sensitivity.

To cultivate the species, the microorganisms were kept in basal growth medium at $37^{\circ} \mathrm{C}$ and $150 \mathrm{rpm}$ for $24 \mathrm{~h}$, and then, this medium was utilized as inoculum for cultivating on MMS. Then, one volume percent of the stabilized basal growth medium was added to MSS medium, and then, SDBS chemical surfactant was filtered and added to the solution.

\section{Asphaltene biodegradation procedure}

To evaluate the effect of microorganism type and the impact of cell surface hydrophobicity on asphaltene biodegradation, two sets of experiments were designed and performed: one with a MMS growth medium and other with MMS and a fraction of SDBS.

For each set of experiments, the desired asphaltene sample was added to the growth medium at 2, 4, and $10 \mathrm{~g} / \mathrm{l}$ initial concentration as the only source of carbon and energy, and the solution was then incubated at $40{ }^{\circ} \mathrm{C}$ and $150 \mathrm{rpm}$ for

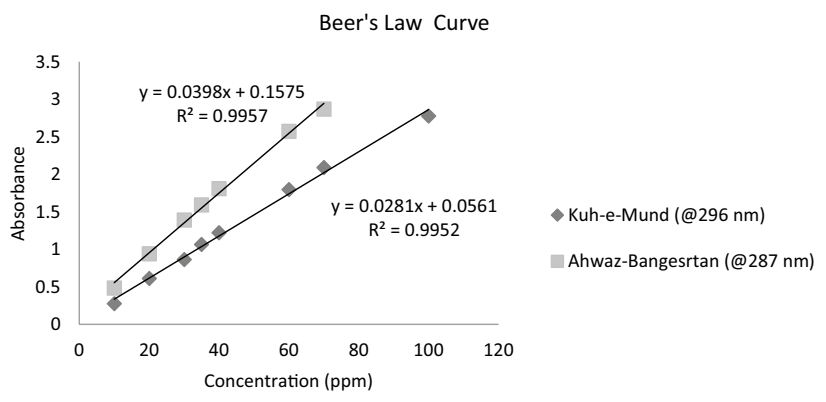

Fig. 2 Standard concentration curve for Ahwaz-Bangestan and Kuhe-Mond asphaltene

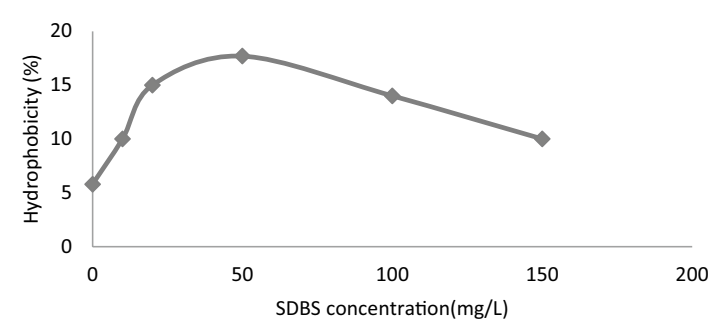

Fig. 3 Effect of SDBS concentration on hydrophobicity

10 days. Concerning the accuracy and reliance of the results, all the experiments performed three times and the results compared.

The last step was to take sample of each solution to evaluate the quantity of the residual asphaltene.

\section{Microorganism hydrophobicity technique}

After the required retention time for asphaltene biodegradation is passed, the solutions were filtered, the residual 

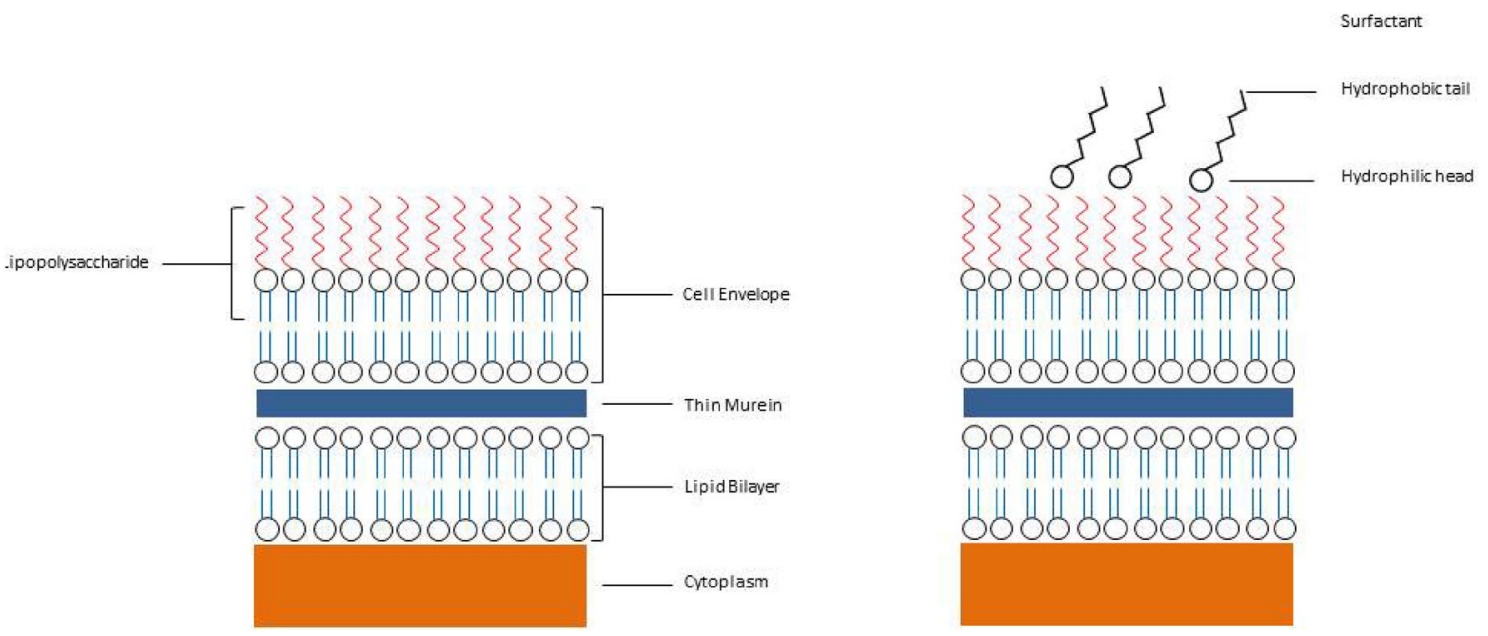

Fig. 4 Effect of surfactant on cell surface properties (left: without surfactant and right: with surfactant)

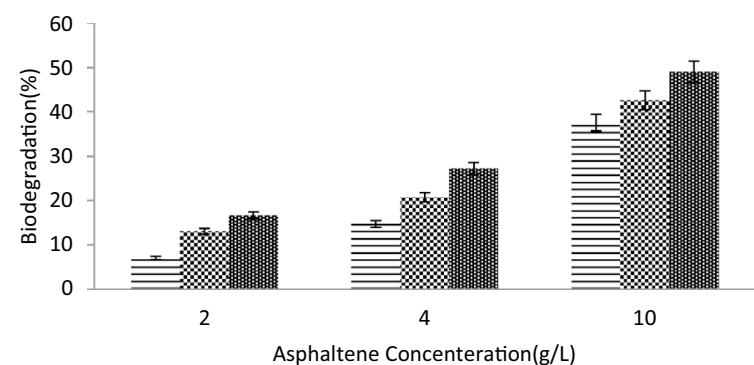

(a)

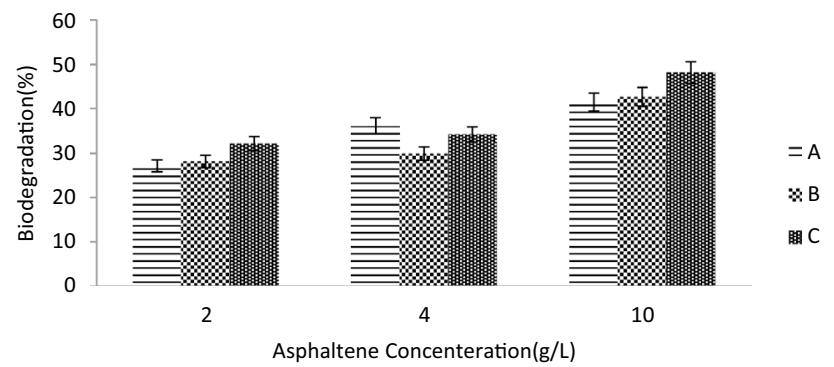

(b)

Fig. 5 Biodegradation of three types of microorganisms at different initial Ahwaz-Bangestan asphaltene concentrations; a without SDBS presence and $\mathbf{b}$ with SDBS presence

asphaltene was measured, and the remained bacterial solution was used for preparing cell suspension solution. The bacterial solution was centrifuged at $4000 \mathrm{rpm}$ for $15 \mathrm{~min}$ to separate the bacterial cells. The segregated cells were then washed with buffer solution. The buffer solution (Sarafzadeh et al. 2014) contained the following composition ( $\mathrm{g} / \mathrm{l})$ : $\mathrm{K}_{2} \mathrm{HPO}_{4} ; 0.56, \mathrm{KH}_{2} \mathrm{PO}_{4} ; 0.22$ and $\mathrm{NaCl} ; 0.80$. When centrifuging finished, cells were washed twice with buffer, and then, the cells began to suspend in buffer solution with each wash. In the next step, the suspension centrifuged at

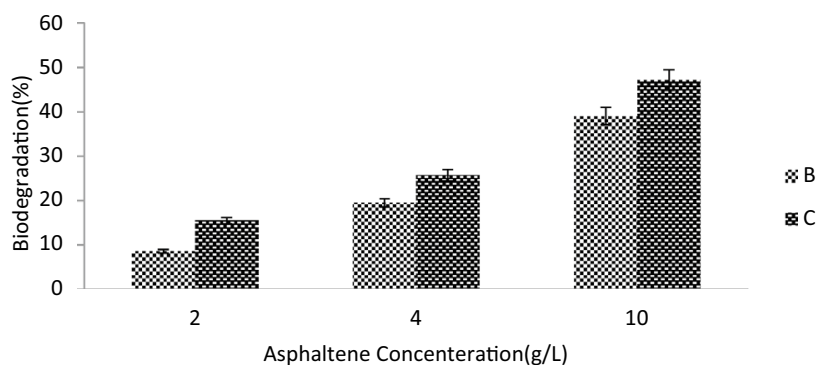

(a)

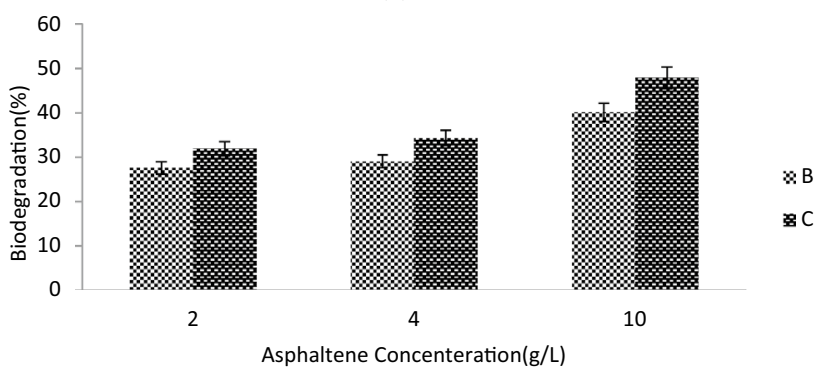

(b)

Fig. 6 Biodegradation of two types of microorganisms at different initial Kuh-e-Mond asphaltene concentrations: a without SDBS presence and $\mathbf{b}$ with SDBS presence

$3000 \mathrm{rpm}$ for $10 \mathrm{~min}$ and the cells accumulated in the bottom. The result was a cell suspension in buffer solution with 0.1 optical density.

Microbial surface hydrophobicity was evaluated by the microbial adhesion to the hydrocarbon method (MATH) (Rosenberg and Rosenberg 1981). The prepared cell suspension was exposed to dodecane with 0.2:2.1 ratios and after 2 min of vortex, left untouched for $20 \mathrm{~min}$ until the phases separated. To quantify the hydrophobicity, the following equation was used: 


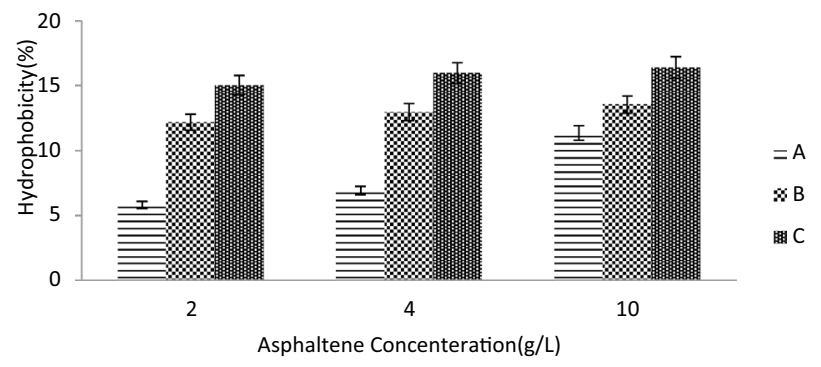

(a)

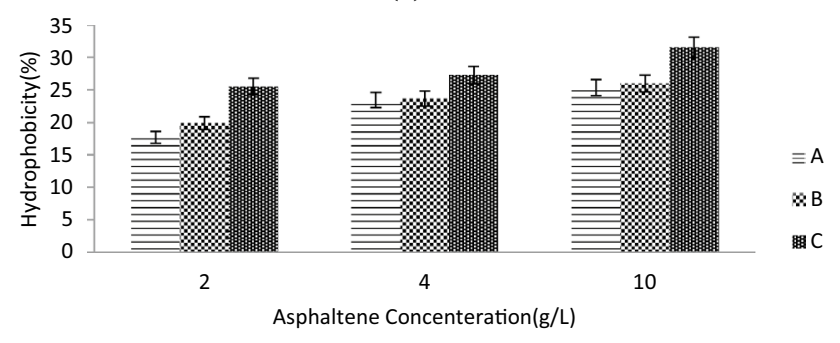

(b)

Fig. 7 Hydrophobicity of three types of microorganisms at different initial Ahwaz-Bangestan asphaltene concentrations: a without SDBS presence and $\mathbf{b}$ with SDBS presence

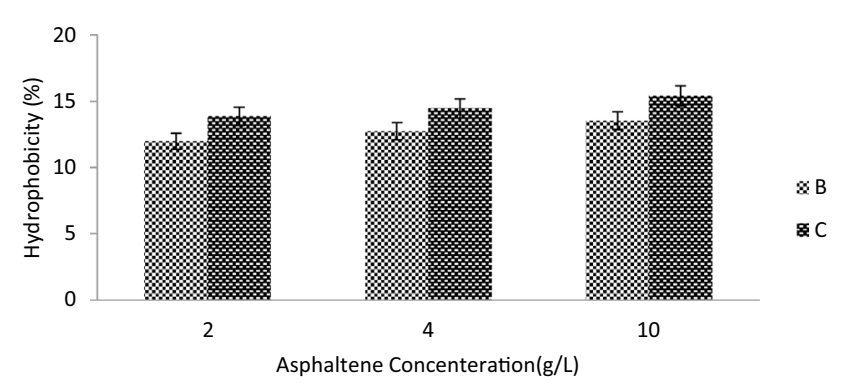

(a)

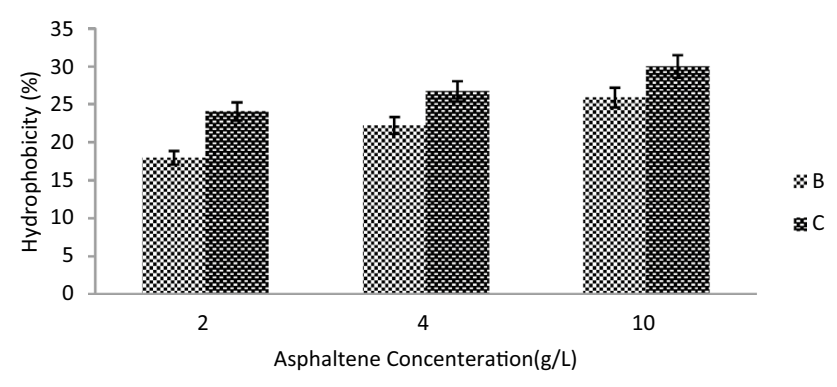

(b)

Fig. 8 Hydrophobicity of two types of microorganisms at different initial Kuh-e-Mond asphaltene concentrations: a without SDBS presence and $\mathbf{b}$ with SDBS presence

Hydrophobicity $(\%)=\frac{\text { Initial OD }(0.1)-\text { Final OD }(20 \mathrm{~min})}{\text { Initial OD }(0.1)} \times 100$

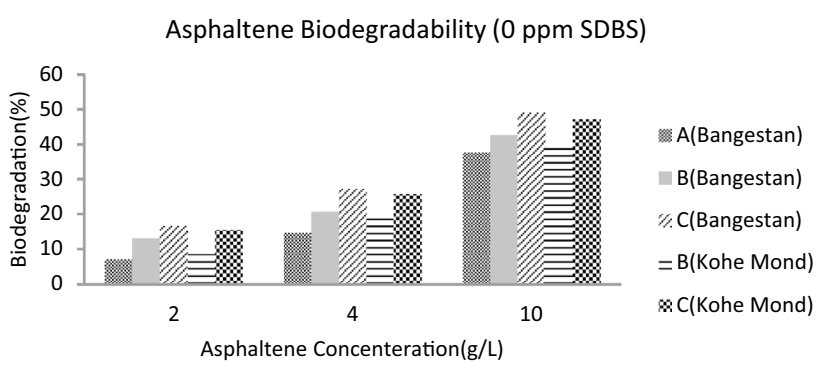

(a)

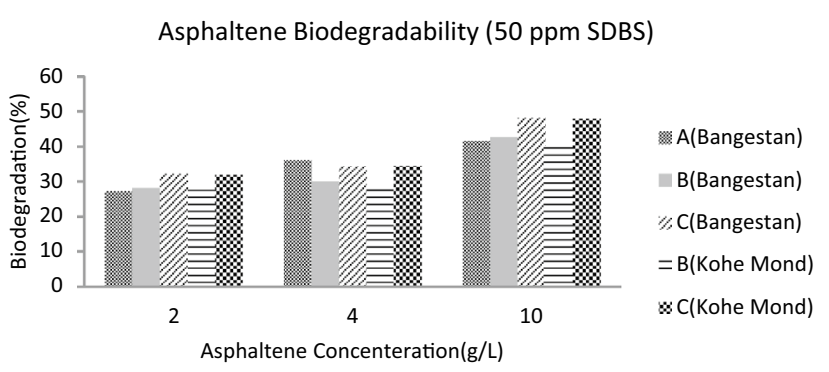

(b)

Fig. 9 Effect of types of microorganisms on Ahwaz-Bangestan and Kuh-e-Mond asphaltene biodegradation: a without SDBS presence and $\mathbf{b}$ with SDBS presence

Concerning the accuracy of the test, the adverse effect of micro emulsion formation after vortex on optical density measurement was eliminated by a quality control test at which MATH was performed on the buffer alone (without the cells) and the results were used to adjust the reading of the spectrophotometer.

\section{Quantification of asphaltene biodegradation}

Spectrophotometry technique was used to determine the concentration of the remained asphaltene in the microorganism growth medium. In the first stage, the standard concentration curve was determined by first obtaining the wavelength of maximum absorbance of two standard solutions with known concentrations, and then, the solutions were introduced to the spectrophotometer analyzer. In this study, the solution of asphaltene in toluene in different fractions was used as a standard solution. To quantify asphaltene biodegradation, the remained amount of asphaltene in the growth medium was filtered and dissolved in toluene, and then, it was introduced to the spectrophotometer analyzer.

\section{Wettability alteration measurement}

To investigate the wettability alteration of the glass surface, aging process by synthetic oil was used. $0.3 \mathrm{~g}$ of the extracted asphaltene powder was combined with 11 of a mixed solution of heptane and toluene with volume ratio of $55-45 \%$ and stirred for an hour. Glass slides kept in the 
solution for 7 days at $40{ }^{\circ} \mathrm{C}$ and then autoclaved, and the wettability was measured. This procedure altered the wettability of the glass slides from water wet to oil wet (Karimi et al. 2012).

The asphaltene covered (Ahwaz-Bangestan and Kuh-eMond) glass slides which suspended in growth medium, bacteria solution, and bacteria solution with chemical surfactant; then, the glass slides used for wettability alteration measurement and IFT tests performed on the solutions.

For wettability alteration measurement, sessile drop method was used. The glass slides were placed in a glass container filled with heptane, and using a KRUSS DSA100 , a droplet of water was injected to the glass container, released in heptane phase, and perched on the glass slide. The droplet image captured via a high precision camera and contact angle measured with symmetric droplet shape analysis method. This experimental procedure repeated three times for each glass slide sample to assure the accuracy of the results.

\section{Results and discussion}

Using the method describing earlier, the wavelength of maximum absorbance for Ahwaz-Bangestan and Kuh-e-Mond asphaltene solution in toluene was determined to be $287 \mathrm{~nm}$ and $296 \mathrm{~nm}$, respectively. Using these values, the standard concentration curves are shown in Fig. 2.

To determine the optimum concentration of SDBS surfactant for hydrophobicity alteration, MATH was performed on $2 \mathrm{~g} / \mathrm{l}$ of Ahwaz-Bangestan asphaltene using different SDBS concentration. The optimum SDBS concentration was measured to be 50 ppm, as shown in Fig. 3.

Figure 3 shows that, with an increase of SDBS concentration to $50 \mathrm{ppm}$, hydrophobicity increases which implies that even a trace of chemical surfactant can affect the hydrophobicity significantly (Fig. 4). At concentrations above $50 \mathrm{mg} / \mathrm{l}$, a decreasing trend can be observed. This might be the result of existence of microemulsion in the solution, cell surface destruction by surfactant at higher concentration,

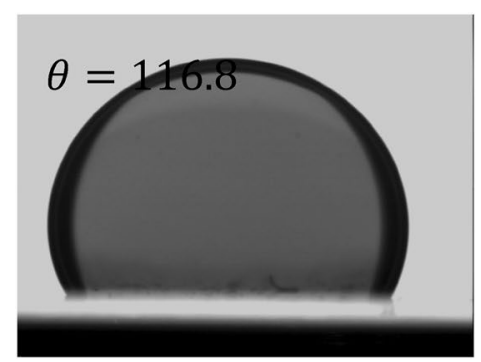

1

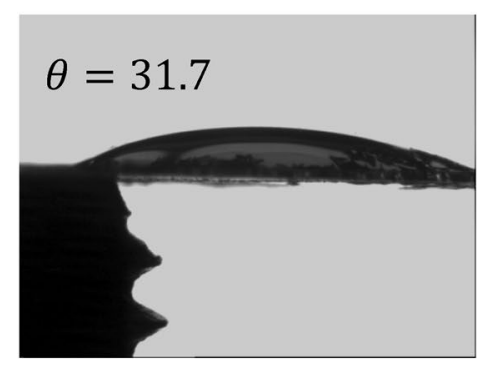

4

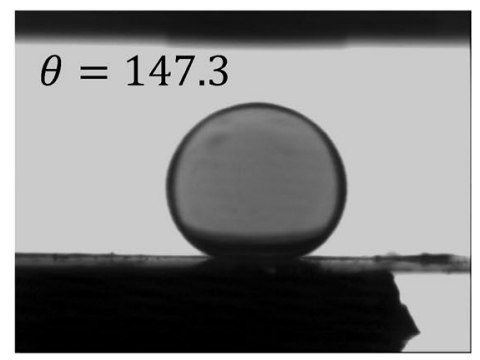

2

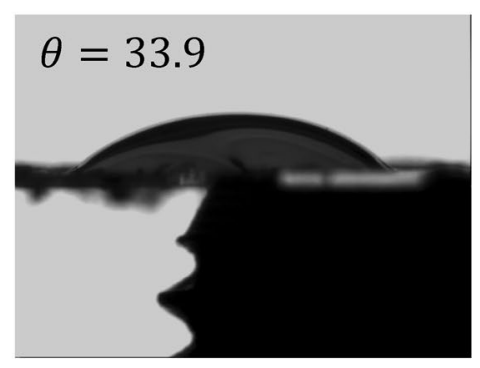

5

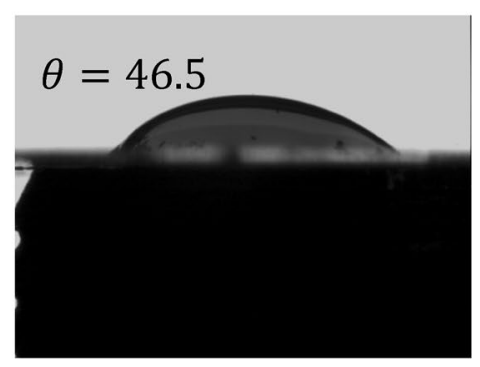

7

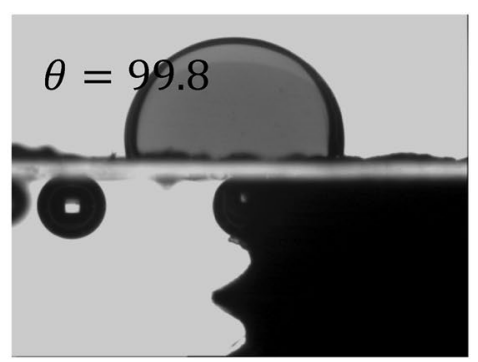

3

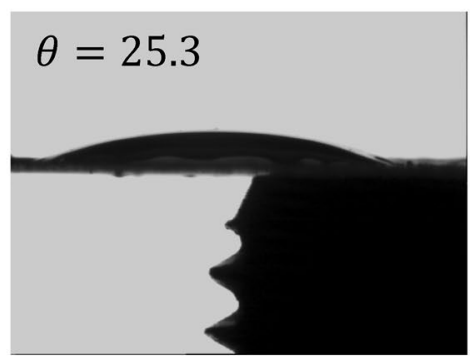

6

Fig. 10 Contact angle measurement for Ahwaz-Bangestan asphaltene samples in different stages 


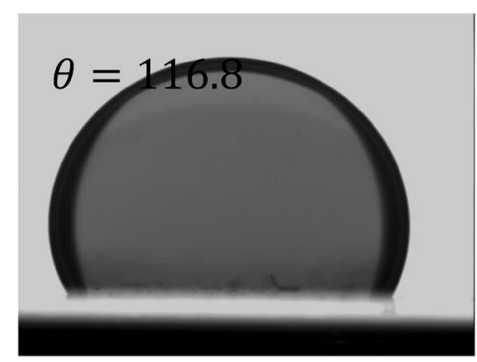

1

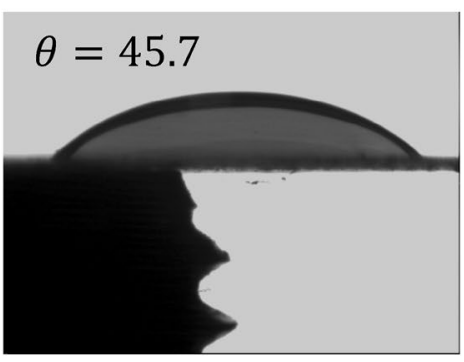

4

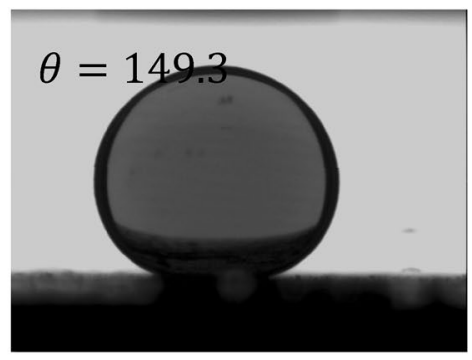

2

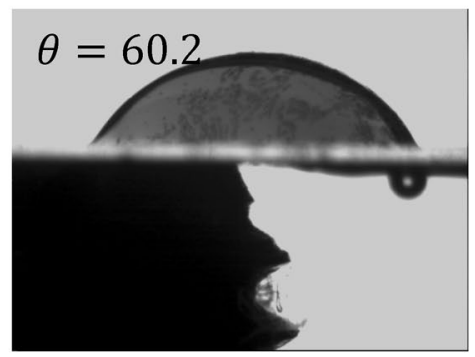

5

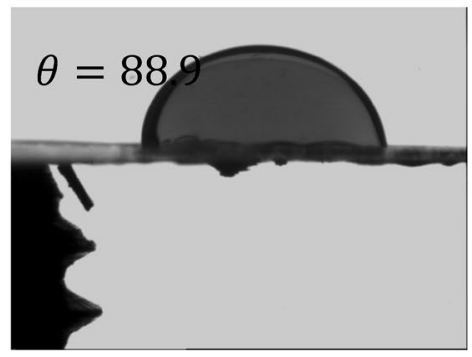

7

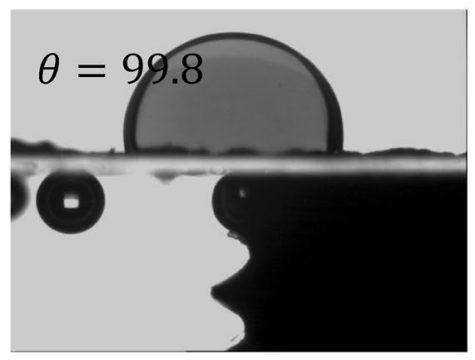

3

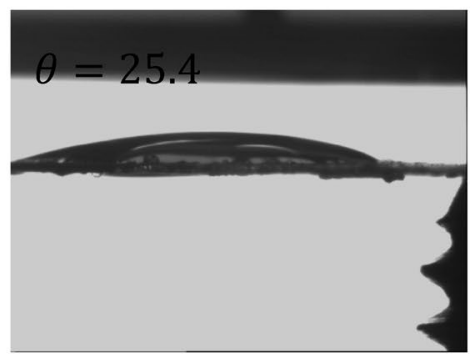

6

Fig. 11 Contact angle measurement for Kuh-e-Mond asphaltene samples in different stages

preferential metabolism, and surfactant adoption for biodegradation. In this study, $50 \mathrm{mg} / \mathrm{l} \mathrm{SDBS}$ concentration as the optimum value was used.

Figure 5 presents the trend of biodegradation of AhwazBangestan sample with type A, B, and C bacteria (see Table 1), respectively. The effects of the initial asphaltene concentrations (2, 4 and $10 \mathrm{~g} / \mathrm{l})$ and presence of SDBS on asphaltene biodegradation are also demonstrated in these figures. As mentioned earlier, each experiment carried out three times to check the accuracy of the results.

Figure 6 presents the results of the same biodegradation tests on Kuh-e-Mond asphaltene sample at different hydrophobicities.

Figure 7 demonstrates the results of MATH tests on Ahwaz-Bangestan sample with type A, B, and C bacteria at the initial asphaltene concentrations $(2,4$ and $10 \mathrm{mg} / \mathrm{l})$. The effect of SDBS surfactant on microorganism hydrophobicity is also presented in this figure.
Figure 8 presents the results of the same tests on Kuh-eMond asphaltene sample.

The results show that, with increase in the initial asphaltene concentration, biodegradation increases for both cases of with and without the presence of surfactant. This is postulated that different factors including increased carbon source for microorganisms and improved mass transfer would be the effective parameters.

According to the comparative results of biodegradation and hydrophobicity experiments for Ahwaz-Bangestan oil sample in without Surfactant condition (Figs. 5a, 7a), bacteria type $\mathrm{C}$ has the most potential for biodegradation which also shows higher hydrophobicity.

The same comparative results for Ahwaz-Bangestan asphaltene sample in the presence of SDBS (Figs. 5b, 7b) is concluded that adding the right amount of surfactant would affect cell surface properties and alter the hydrophobicity leading to increase in bacteria adhesion to asphaltene which boost the biodegradation. At higher asphaltene 
Fig. 12 Schematic diagram of the drop shape analyzer

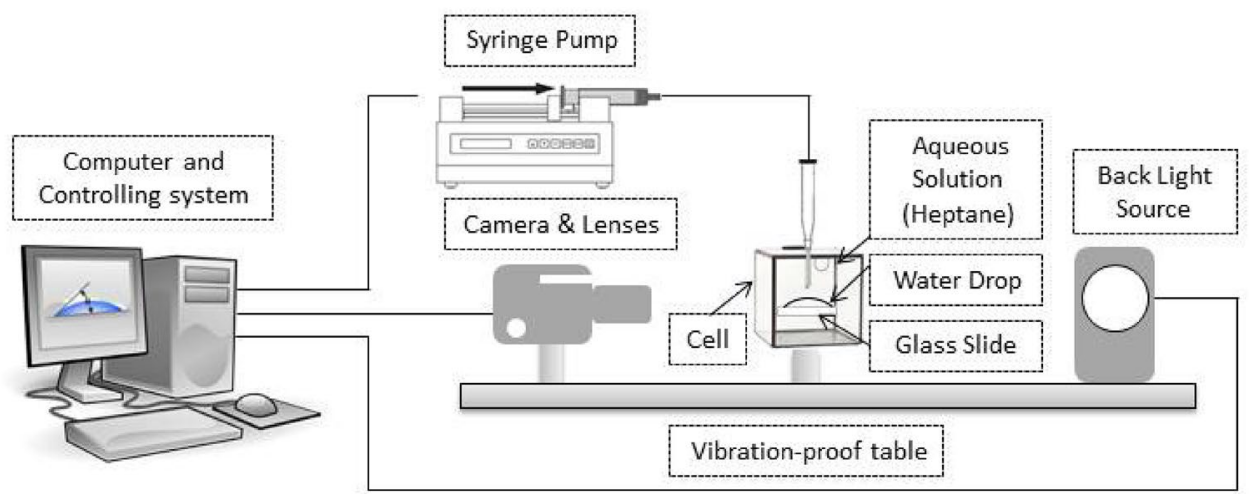

concentrations, adding more surfactant, despite changing microorganisms' cell surface hydrophobicity, had a little impact on biodegradation which can be attributed to the presence of sufficient amounts of asphaltene available for microorganisms.

Figures 6 and 8 present the same experimental results on Kuh-e-Mond asphaltene without and with the presence of SDBS.

Comparative results of Ahwaz-Bangestan and Kuh-eMond asphaltene biodegradation without the presence of surfactant are demonstrated in Fig. 9a.

The results show that Ahwaz-Bangestan asphaltene biodegradation at the same conditions of the initial concentration and the type of employed microorganism is little more than Kuh-e-Mond, which demonstrates that asphaltene type has a low impact on the biodegradation. This might be the result of the similar molecular structure of the asphaltene samples and the slight difference in biodegradation level may be due to the difference in Sp.Gr between the two asphaltene samples. Higher Sp.Gr results in increased resistance to biodegradation.

Figure $9 \mathrm{~b}$ presents the comparative results of AhwazBangestan and Kuh-e-Mond asphaltene biodegradation with the presence of surfactant.

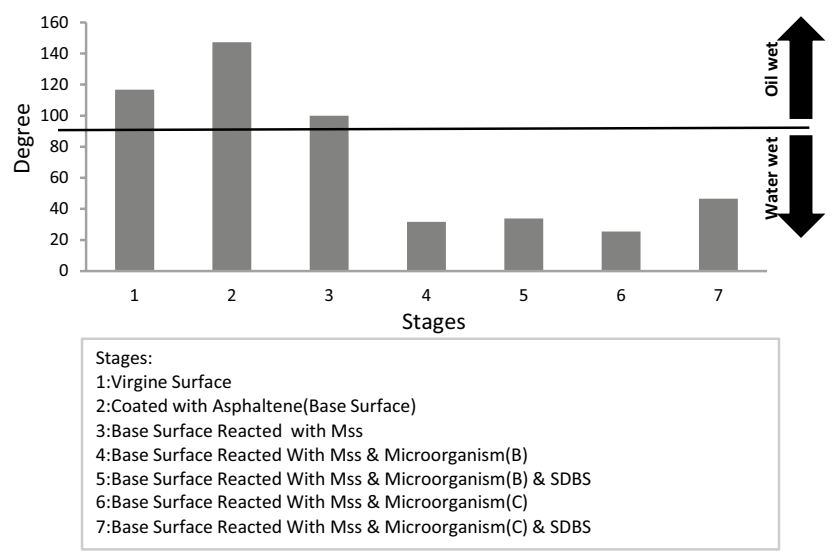

Fig. 13 Contact angle measurement for Ahwaz-Bangestan asphaltene samples
Figure $9 \mathrm{~b}$ supports the earlier conclusion on small effect of asphaltene type on biodegradation.

To develop the required experimental data for wettability alteration measurements, contact angle measurement was performed on the asphaltene covered glass slides in microorganism growth medium with and without surfactant using the method discussed earlier in this work (Figs. 10, 11). Figure 12 presents the schematic diagram of the drop shape analyzer.

Figures 13 and 14 demonstrate the results of contact angle experiment on Ahwaz-Bangestan and Kuh-e-Mond asphaltene samples, respectively.

It is concluded that the presence of microorganism alters the wettability from oil wet to water wet. This phenomenon is first due to accumulation of microorganisms on the glass surface to consume the polar and asphaltenic component which are adhered to the surface and second an increase in surface roughness due to adhesion of asphaltene which will assist the bacteria to stick to the surface. The result will be

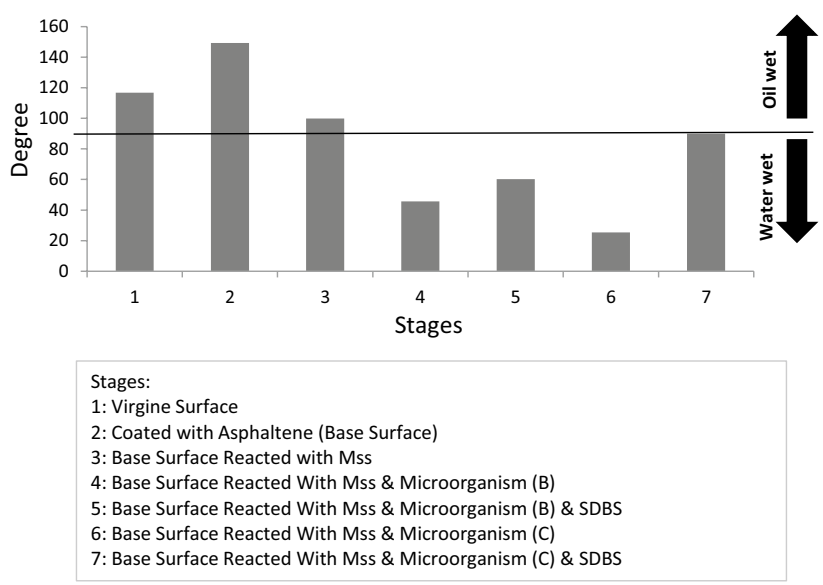

Fig. 14 Contact angle measurement for Kuh-e-Mond asphaltene samples 
Fig. 15 Effect of surfactant on wettability of glass surface in the presence of microorganisms

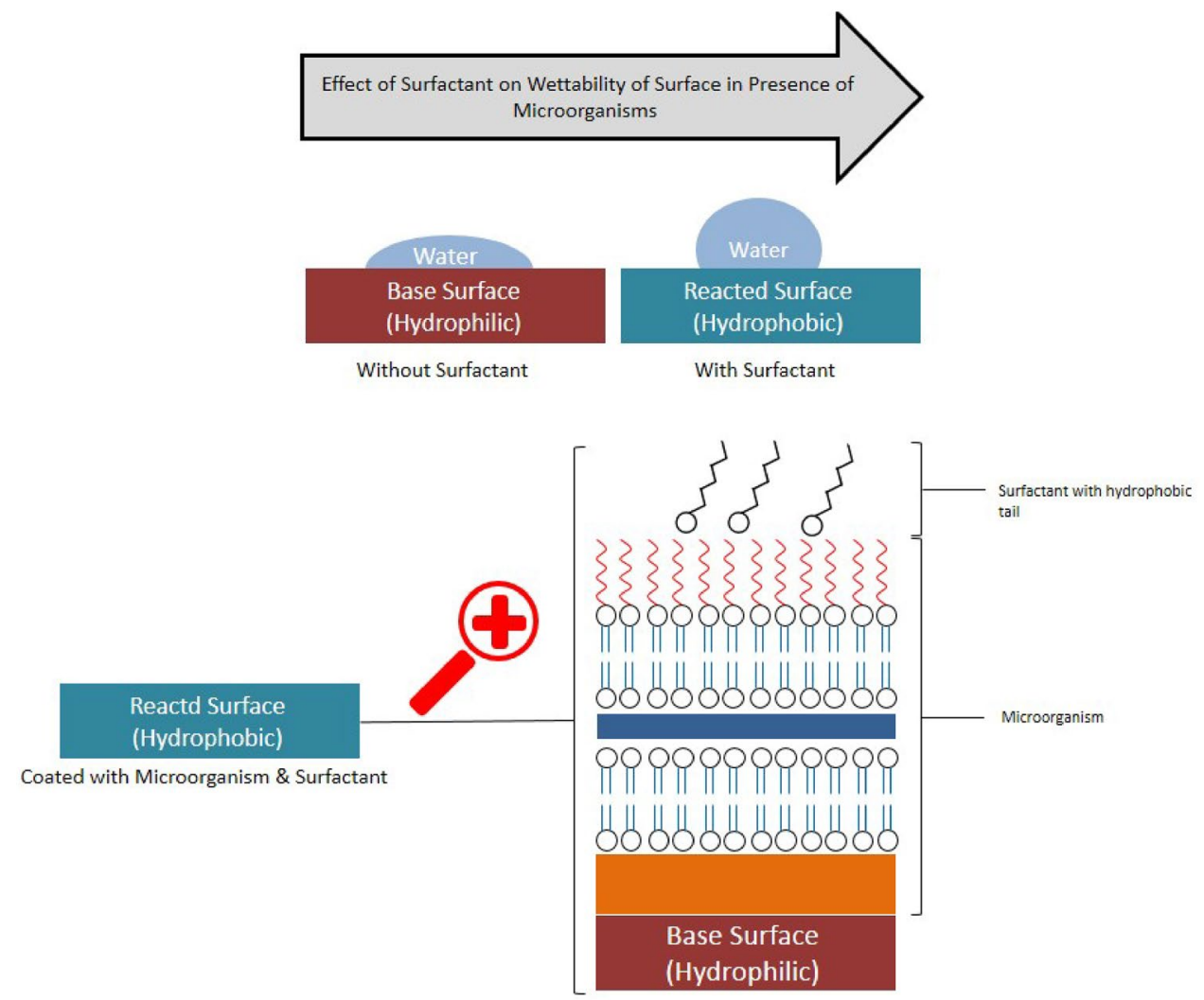

a formation of biofilm around the surface which affect the wettability.

With presence of surfactant for both microorganism types, contact angle is higher than "without surfactant" samples. This might be due to a change in microorganism cell surface properties and an increase in their hydrophobicity (Fig. 15).

\section{Conclusions}

Asphaltene as complex structure normally resists biodegradation; however, providing favorable conditions including: appropriate microorganism selection, sufficient time, presence of necessary minerals for nourishing the bacteria, temperature, and neutral medium (not acidic; not basic) enhances asphaltene biodegradation. The results of this study show that cell surface hydrophobic properties have critical impact on bacteria adhesion to non-water soluble hydrocarbons which enhances biodegradation. It is also concluded that the presence of chemical surfactants directly affects cell surface properties and changes the level of hydrophobicity. The results indicated that asphaltene type is not critical for the biodegradation process at least for the different types of asphaltene structures utilized in this study. The results show higher biodegradation for Ahwaz-Bangestan asphaltene in the same experimental condition, initial asphaltene concentration, and the amount of utilized surfactant compared to the samples from Kuh-e-Mond.

It is also concluded that microorganisms altered the surface wettability to hydrophilic. Wettability measurement tests on the glass slides showed that bacteria adhesion to surface has the main contribution in changing the wettability to hydrophilic. In the presence of chemical surfactant, the degree of contact angle increases. This phenomenon could be the result of increased hydrophobicity of the bacteria cell surface in the presence of surfactant.

Acknowledgements The author would like to thank EOR Research Center in School of Chemical, Gas and Petroleum Engineering, Shiraz University for laboratory instruments and financial supports.

Open Access This article is distributed under the terms of the Creative Commons Attribution 4.0 International License (http://creativeco mmons.org/licenses/by/4.0/), which permits unrestricted use, distribution, and reproduction in any medium, provided you give appropriate credit to the original author(s) and the source, provide a link to the Creative Commons license, and indicate if changes were made.

\section{References}

Abbasnezhad H, Gray MR, Foght JM (2008) Two different mechanisms for adhesion of Gram-negative bacterium, Pseudomonas 
fluorescens LP6a, to an oil-water interface Colloids Surf B Biointerfaces 62:36-41

Ali LH, Al-Ghannam KA (1981) Investigations into asphaltenes in heavy crude oils. I. Effect of temperature on precipitation by alkane solvents. Fuel 60:1043-1046

Amin JS, Nikooee E, Ghatee M, Ayatollahi S, Alamdari A, Sedghamiz $\mathrm{T}$ (2011) Investigating the effect of different asphaltene structures on surface topography and wettability alteration. Appl Surf Sci 257:8341-8349

Bressler DC, Gray MR (2003) Transport and reaction processes in bioremediation of organic contaminants. 1. Review of bacterial degradation and transport. Int J Chem React Eng 1:1

Escobedo J, Mansoori GA (2010) Heavy-organic particle deposition from petroleum fluid flow in oil wells and pipelines. Pet Sci 7:502-508

Etoumi A, El Musrati I, El Gammoudi B, El Behlil M (2008) The reduction of wax precipitation in waxy crude oils by Pseudomonas species. J Ind Microbiol Biotechnol 35:1241-1245

Ferrari M, Albornoz C, Neirotti E (1993) Biodegradability in soil of residual hydrocarbons in petroleum tank bottoms. Revista Argentina de Microbiologia 26:157-170

Gray RM (1994) Upgrading petroleum residues and heavy oils. CRC Press, Boca Raton

Jahromi H, Fazaelipoor M, Ayatollahi S, Niazi A (2014) Asphaltenes biodegradation under shaking static conditions. Fuel 117:230-235

Kaczorek E, Chrzanowski Ł, Pijanowska A, Olszanowski A (2008) Yeast and bacteria cell hydrophobicity and hydrocarbon biodegradation in the presence of natural surfactants: rhamnolipides and saponins. Bioresour Technol 99:4285-4291

Kaczorek E, Urbanowicz M, Olszanowski A (2010) The influence of surfactants on cell surface properties of Aeromonas hydrophila during diesel oil biodegradation. Colloids Surf B Biointerfaces 81:363-368

Karimi M, Mahmoodi M, Niazi A, Al-Wahaibi Y, Ayatollahi S (2012) Investigating wettability alteration during MEOR process, a micro/macro scale analysis. Colloids Surf B 95:129-136

Kloos K, Schloter M, Meyer O (2006) Microbial activity in an acid resin deposit: biodegradation potential and ecotoxicology in an extremely acidic hydrocarbon contamination. Environ Pollut 144:136-144

Kor P, Kharrat R, Ayoubi A (2017) Comparison and evaluation of several models in prediction of asphaltene deposition profile along an oil well: a case study. J Pet Explor Prod Technol 7:497-510

Liao Y, Geng A, Huang H (2009) The influence of biodegradation on resins and asphaltenes in the Liaohe Basin. Org Geochem 40:312-320

Mansoori GA (2009) A unified perspective on the phase behaviour of petroleum fluids. Int J Oil Gas Coal Technol 2:141-167

Mansoori G, Elmi A (2010) Remediation of asphaltene and other heavy organic deposits in oil wells and in pipelines ELMI a Sarlar. J Reserv Pet Eng 4:12-23
Mullins OC (2008) Review of the molecular structure and aggregation of asphaltenes and petroleomics. SPE J 13:48-57

Pendrys JP (1989) Biodegradation of asphalt cement-20 by aerobic bacteria. Appl Environ Microbiol 55:1357-1362

Pineda-Flores G, Mesta-Howard AM (2001) Petroleum asphaltenes: generated problematic and possible biodegradation mechanisms. Revista Latinoamericana de Microbiologia-Mexico 43:143-150

Rabbani E, Davarpanah A, Memariani M (2018) An experimental study of acidizing operation performances on the wellbore productivity index enhancement. J Pet Explor Prod Technol 1:1-11

Reddy MV, Devi MP, Chandrasekhar K, Goud RK, Mohan SV (2011) Aerobic remediation of petroleum sludge through soil supplementation: microbial community analysis. J Hazard Mater 197:80-87

Rosenberg M, Rosenberg E (1981) Role of adherence in growth of Acinetobacter calcoaceticus RAG-1 on hexadecane. J Bacteriol 148:51-57

Salager J-L, Marquez N, Graciaa A, Lachaise J (2000) Partitioning of ethoxylated octylphenol surfactants in microemulsion-oil-water systems: influence of temperature and relation between partitioning coefficient and physicochemical formulation. Langmuir 16:5534-5539

Sarafzadeh P, Niazi A, Oboodi V, Ravanbakhsh M, Hezave AZ, Ayatollahi SS, Raeissi S (2014) Investigating the efficiency of MEOR processes using Enterobacter cloacae and Bacillus stearothermophilus SUCPM\# 14 (biosurfactant-producing strains) in carbonated reservoirs. J Pet Sci Eng 113:46-53

Silva TF, Azevedo DA, Rangel MD, Fontes RA, Neto FRA (2008) Effect of biodegradation on biomarkers released from asphaltenes. Org Geochem 39:1249-1257

Tavassoli T, Mousavi S, Shojaosadati S, Salehizadeh H (2012) Asphaltene biodegradation using microorganisms isolated from oil samples. Fuel 93:142-148

Torrealba V, Johns RT (2017) Coupled interfacial tension and phase behavior model based on micellar curvatures. Langmuir 33:13604-13614

Torrealba VA, Johns RT (2018) Partition-coefficient relations for improved equation-of-state description of microemulsion-phase behavior. SPE J. https://doi.org/10.2118/179845-PA

Zhang Y, Fang S, Tao T, Xiong Y, Duan M (2016) Influence of asphaltene concentration on the interfacial properties of two typical demulsifiers. J Dispers Sci Technol 37:1453-1459

Publisher's Note Springer Nature remains neutral with regard to jurisdictional claims in published maps and institutional affiliations. 